\section{Pharmaceutical Research}

June 2008, Volume 25, Number 6, Pages 1318-1326

http://dx.doi.org/10.1007/s11095-007-9481-3

(c) 2008 Springer. Part of Springer Science+Business

Media

The original publication is available at http://www.springerlink.com
Archimer, archive institutionnelle de l'Ifremer http://www.ifremer.fr/docelec/

\title{
Aerodynamical, Immunological and Pharmacological Properties of the Anticancer Antibody Cetuximab Following Nebulization
}

\author{
Agnès Maillet ${ }^{1}$, Nicolas Congy-Jolivet ${ }^{2}{ }^{3}$, Sandrine Le Guellec ${ }^{4}$, Laurent Vecellio ${ }^{1}$, Sophie Hamard ${ }^{1}$, \\ Yves Courty ${ }^{1}$, Anthony Courtois ${ }^{5,6}$, Francis Gauthier ${ }^{1}$, Patrice Diot ${ }^{1,3}$, Gilles Thibault ${ }^{2,3}$, Etienne \\ Lemarié $^{1,3}$ and Nathalie Heuzé-Vourc' $h^{1,7}$,
}

\footnotetext{
${ }^{1}$ U618, Protéases et vectorisation Pulmonaires, Université François-Rabelais de Tours, Tours, France

2 UPRES EA 3853, Immuno-Pharmaco-Génétique des Anticorps thérapeutiques (IPGA), Université François-

Rabelais de Tours, Tours, France

${ }^{3}$ CHRU de Tours, 37000 Tours, France

${ }^{4}$ Atomisor, DTF, 42003 Saint Etienne, France

${ }^{5}$ Laboratoire de Thérapie Cellulaire et Immunobiologie du Cancer, CHU Morvan de Brest, Université de Bretagne Occidentale, Brest, France

${ }^{6}$ Laboratoire de Biotechnologie et Molécules marines, IFREMER, Plouzané, France

${ }^{7}$ INSERM U618-Faculté de Médecine, 10 Boulevard Tonnellé, 37032 Tours cedex 1, France
}

*: Corresponding author : Heuzé N., email address : nathalie.heuze@univ-tours.fr

\begin{abstract}
:
Purpose Despite an increasing interest in the use of inhalation for local delivery of molecules for respiratory diseases and systemic disorders, methods to deliver therapy through airways has received little attention for lung cancer treatment. However, inhalation of anticancer drugs is an attractive alternative route to systemic administration which results in limited concentration of the medication in the lungs, and triggers whole-body toxicity. In this study, we investigated the feasibility of nebulization for therapeutic antibodies, a new class of fully-approved anticancer drugs in oncology medicine.

Materials and methods Cetuximab, a chimeric IgG1 targeting the epidermal growth factor receptor (EGFR), was nebulized using three types of delivery devices: a jet nebulizer PARI LC+®, a mesh nebulizer AeronebPro ${ }^{\circledR}$ and an ultrasonic nebulizer SYST'AM ${ }^{\circledR}$ LS290. Aerosol size distribution was measured using a cascade impactor and aerosol droplets were observed under optical microscopy. The immunological and pharmacological properties of cetuximab were evaluated following nebulization using A431 cells.

Results The aerosol particle clouds generated with the three nebulizers displayed similar aerodynamical characteristics, but the IgG formed aggregates in liquid phase following nebulization with both the jet and ultrasonic devices. Flow cytometry analyses and assays of EGFRphosphorylation and cell growth inhibitions on A431 demonstrated that both the mesh and the jet nebulizers preserved the binding affinity to EGFR and the inhibitory activities of cetuximab.

Conclusions Altogether, our results indicate that cetuximab resists the physical constraints of nebulization. Thus, airway delivery represents a promising alternative to systemic administration for local delivery of therapeutic antibodies in lung cancer treatment.
\end{abstract}

Keywords: aerosol - aggregation - anticancer antibody - cetuximab - lung cancer - nebulizer 


\section{Introduction}

The lung is the most common site of metastasis from primary neoplasia, and lung cancer is the leading cause of cancer-related deaths worldwide. Despite the availability of new drugs that target cancer cells and more efficient chemotherapeutics, the outcome for the treatment of lung cancer has not changed dramatically and the cure rate remains one of the lowest among all malignancies (1). The delivery of an inadequate drug concentration to the tumor site after intravenous or oral administration is a potential reason for the limited efficacy of new therapeutics.

Inhalation is an attractive delivery route for anticancer drugs. It offers several potential advantages over systemic and oral routes, including loco-regional delivery to the lungs providing high drug concentration, avoidance of the first-pass metabolic degradation in the liver and reduction of systemic side effects $(2,3)$. This route has been used for a long time to administer local-acting agents in respiratory diseases (i.e. asthma, infections). Its use is also being adopted for the delivery of systemic-acting therapeutics whether they are small molecules or macromolecules (3-6). As a hallmark of success, the first inhaled insulin powder, Exubera ${ }^{\circledR}$, has recently been approved in Europe and US for the treatment of adult patients with type 1 or type 2 diabetes (7).

\footnotetext{
Although preclinical studies have shown significant antitumor activity of aerosolized drugs (8-12), and phase-I clinical trials demonstrated the feasibility of nebulization and the safety of anticancer therapeutics delivered through the airways in humans (13-16), inhalation remains minimally explored as a method of drug administration for lung cancer treatment. Aerosolization has been tested on few anticancer drugs. Among new anticancer molecules,
} 
therapeutic antibodies have emerged as a new class of successful drugs for hematopoietic malignant neoplasia and solid tumours, becoming a major strategy for therapy in oncology and representing half of the anticancer molecules in development in industry. Currently nine naked or conjugated antibodies have been approved by the Food and Drug Administration (FDA) and the European MEdicines Agency (EMEA) for human cancer treatments and numerous antibodies are in late clinical trial phases $(17,18)$.

Therapeutic monoclonal antibodies (mAb) are typically of the IgG1 subclass and correspond to large glycoproteins with a molecular mass around $150 \mathrm{kDa}$. Unlike synthetic small molecules for which lung metabolism is minimal, proteins are highly susceptible to hydrolysis occurring inside cells that engulf foreign particles, such as macrophages, within the lung (3). Previous studies delineated the potential of solid aerosols for pulmonary delivery of antibodies (19-21) and showed that manipulations of aerosol characteristics allow control of Ig release and prevent phagocytosis. However, spray-drying of pure proteins in aqueous solutions often resulted in the production of aggregates and/or loss of therapeutic activity requiring changes in drug formulation.

Although nebulization of large proteins into airways was widely debated, recent data demonstrated that proteins could be efficiently administered through airways as liquid aerosols when conjugated to the constant Fc region of IgG. The high bioavailability of those Fc-conjugated macromolecules was achieved via exploitation of the FcRn transport/protection pathway of antibody $(4,22,23)$. Thus, nebulization that allows direct utilization of drugs in solution, such as anticancer antibodies, might represent an alternative to dry-powder inhalers for local delivery of mAb in lung cancer treatment. 
Because the nebulized anticancer antibody needs to be fully-active when delivered to patients to be efficient, this paper attempts to determine whether mAb resists the physical constraints of nebulization. Herein, we investigated the impact of three different types of nebulizers on aggregation, and the immunological and pharmacological properties of cetuximab, a chimeric IgG1 targeting EGFR, which is currently being tested in i.v. from in clinical trials for lung cancer treatment (24-26). 


\section{Material and Methods}

\section{Cell culture and antibodies}

The A431 human epidermoid carcinoma cells and the human bronchioalveaolar carcinoma cell line A549 were obtained from ATCC (American Type Culture Collection). The cells were grown at $37{ }^{\circ} \mathrm{C}$ in an atmosphere of $5 \% \mathrm{CO}_{2}$ in Roswell Park Memorial Institute Medium (RPMI-1640) containing 10\% fetal bovine serum (FBS), 100U/mL penicillin, $100 \mu \mathrm{g} / \mathrm{mL}$ streptomycin.

Cetuximab and rituximab (control irrelevant antibody) were purchased from Merck KGaA (Darmstadt, Germany) and Roche (Fontenay-sous-Bois, France) respectively. Cetuximab and rituximab were supplied at a concentration of $2 \mathrm{mg} / \mathrm{mL}$ and $10 \mathrm{mg} / \mathrm{mL}$ respectively, as neutral aqueous solutions (sodium phosphate buffer).

Polyclonal antibodies anti-total EGFR (SC-03) and anti-phospho EGFR (pY1068) were obtained from Santa Cruz Biotechnology, Inc. (Santa Cruz, CA) and from Merck KGaA (Darmstadt, Germany) respectively. FITC-conjugated $\mathrm{F}(\mathrm{ab})_{2}$ anti-human $\operatorname{IgG}$ and peroxidase-conjugated anti-rabbit IgG were respectively purchased from Jackson Immuno Research (Cambridgeshire, UK) and Santa Cruz Biotechnology, Inc. (Santa Cruz, CA).

\section{Nebulization and characterization of aerosol particles}

Cetuximab was nebulized with three different devices: (1) a jet nebulizer, PARI LC+ ${ }^{\circledR}$ (PARI, Germany) using an air compressor that breaks the medication into small breathable particles, (2) an ultrasonic nebulizer, SYST' AM ${ }^{\circledR}$ LS290 (SYST'AM, France) applying high frequency vibration through medication solutions, creating standing waves that generate aerosol and (3) a mesh nebulizer, AeronebPro ${ }^{\circledR}$ (Aerogen, USA) using a vibrational element with a micropumping action to create aerosol particles. 
Briefly, $9 \mathrm{~mL}$ of cetuximab were loaded in each nebulizer (in triplicate) and samples were collected in liquid phase with an impinger (Ace Glass Inc., Vineland, USA) operating at an air flow rate of $12.6 \mathrm{~L} / \mathrm{min}$. The total period of operation did not overtake 20 minutes. A BCA (BiCinchoninicAcid) Protein Assay Kit (Perbio Sciences, France) was used to control cetuximab concentration following nebulization, and volumes of nebulized cetuximab were adapted for cell assays. Following nebulization, cetuximab solutions were observed under an optical microscope (Axiovert 25, Zeiss).The number of aggregates per milliliter was calculated using a Malassez heamatocytometer and their sizes estimated.

Particle size distribution was measured using an IMPAQ-GS-1E cascade impactor (California Measurements, USA) under a flow rate of $1 \mathrm{~L} / \mathrm{min}$. The IMPAQ-GS-1E cascade impactor has been calibrated by the manufacturer at $1 \mathrm{~L} / \mathrm{min}$. This air flow rate determines cut off diameters of each stage. The IMPAQ-GS-1E cascade impactor has been used by other authors with the same air flow rate. The advantage of the low flow cascade impactor is to limit the influence of the addition of air to measure the particle size $(27,28)$. The deposited aerosol on each impactor stage was resuspended in PBS containing 1\% SDS. A BCA Protein Assay Kit was then used to determine the mass of antibody deposited on each stage. MMAD and the estimated breathable fraction (namely FPF for fine particle fraction $(<5 \mu \mathrm{m})$ ) were determined using data of cascade impaction of three independent experiments.

\section{$\underline{\text { Recognition of EGF by flow cytometry }}$}

A549 and A431 cells were harvested by trypsinization, washed with phosphate-buffered saline (PBS) and incubated in PBS containing $2 \%$ of FBS (FACS buffer) with native or nebulized cetuximab $(2 \mu \mathrm{g} / \mathrm{mL}$ and $10 \mu \mathrm{g} / \mathrm{mL}$ for A549 and A431 respectively) for 1 hour at $4^{\circ} \mathrm{C}$. Rituximab $(2 \mu \mathrm{g} / \mathrm{mL}$ or $10 \mu \mathrm{g} / \mathrm{mL})$ was used as isotype-matched nonbinding antibody. Subsequently, cells were washed twice with FACS buffer and incubated at $4{ }^{\circ} \mathrm{C}$ in the dark for 
30 minutes with FITC-F(ab')2 anti-human IgG diluted in FACS buffer. After two additional washing steps, cells were resuspended in $0.5 \mathrm{~mL}$ of FACS buffer containing 7-amino actinomycin D (2 $\mu \mathrm{g} / \mathrm{mL})$, which was used to exclude dead cells. Cells were analyzed on an EPICS XL flow cytometer using Expo32 software (Beckman Coulter).

\section{Evaluation of affinity to EGFR by flow cytometry}

A431 cells $\left(1.510^{5}\right)$ were harvested using trypsin and incubated with unlabeled native or nebulized cetuximab $\left(5.10^{-6}\right.$ to $\left.5.10^{-2} \mathrm{mg} / \mathrm{mL}\right)$ for 30 minutes at $4^{\circ} \mathrm{C}$. Then, cells were incubated for 30 minutes at $4{ }^{\circ} \mathrm{C}$ with FITC-cetuximab $(5 \mu \mathrm{g} / \mathrm{mL})$ or with the isotype-matched nonbinding antibody FITC-rituximab $(5 \mu \mathrm{g} / \mathrm{mL})$. After two washes with PBS, cells were resuspended in $0.45 \mathrm{~mL}$ of PBS and analyzed on an EPICS XL flow cytometer using Expo32 software (Beckman Coulter).

\section{Growth inhibition assay}

Cells were plated in a 96-well culture plate at a density of 5,000 cells/well and allowed to grow overnight in appropriate maintenance medium. Twenty-four hours after plating, RPMI1640 was added to the cells with or without cetuximab $(50 \mu \mathrm{g} / \mathrm{mL}$ of native or nebulized antibody). Then, they were incubated for another 48 hours, harvested and counted using a Malassez heamatocytometer. The relative growth was calculated as the ratio of the median control value. Experiments were repeated six times in triplicate with the different types of nebulized cetuximab.

\section{$\underline{\text { Phosphorylation inhibition assay }}$}

A431 cells were seeded on a 6-well plate at a density of $4.10^{5}$ cells/well and allowed to grow overnight in appropriate maintenance cell culture medium. The medium was then replaced 
with RPMI-1640 with or without cetuximab $(50 \mu \mathrm{g} / \mathrm{mL}$ of native or nebulized antibody). After 24 hours incubation, cells were treated with 10ng/mL recombinant EGF for 10 minutes, washed with ice-cold PBS and lyzed with $200 \mu \mathrm{L}$ of RIPA buffer (50 mM Tris-HCl [pH 7.4], $150 \mathrm{mM} \mathrm{NaCl}, 1 \% \mathrm{NP} 40,1 \% \mathrm{SDS}, 50 \mathrm{mM} \mathrm{NaF}, 1 \mathrm{mM}$ sodium orthovanadate, $1 \mathrm{X}$ Protease Inhibitor Cocktail (Sigma, France)). Protein lysates were collected and immediately boiled at $100^{\circ} \mathrm{C}$ for 7 minutes. After 15 minutes centrifugation at $12,000 \mathrm{xg}$, supernatants containing cell proteins were recovered and protein concentration was determined using a BCA Protein Assay.

Protein extracts were separated on a $7.5 \%$ SDS-PAGE and then transferred on PVDF (polyvinyldene difluoride) membranes by electroblotting. The membranes were incubated with $5 \%$ nonfat dry milk diluted in TBS-T (10 mM Tris [pH 7.4], $150 \mathrm{mM} \mathrm{NaCl,} 0.05 \%$ Tween 20) for 1 hour to block nonspecific binding, and were then incubated with either the anti-phospho EGFR IgG or the anti-total EGFR antibody (to control loading equal amounts) under the conditions recommended by the manufacturers. The blots were washed with TBS-T three times and incubated with the appropriate secondary antibody conjugated to HRP for 1 hour. After three additional washes, the membranes were developed using an enhanced chemiluminescence plus detection system (Amersham Biosciences, Buckinghamshire, UK).

\section{$\underline{\text { Statistical analysis }}$}

For growth inhibition assays, the results were expressed as medians and the difference between groups was compared using a Kruskal and Wallis non parametric test. A p value inferior or equal to 0.05 was considered for statistical significance. 


\section{Results}

To analyze the feasibility of nebulizing cetuximab, we used three devices with different technological approaches (a jet nebulizer PARI LC $+{ }^{\circledR}$, a mesh nebulizer AeronebPro ${ }^{\circledR}$ and an ultrasonic nebulizer SYST' AM ${ }^{\circledR}$ LS290) and then evaluated the aerodynamical characteristics of cetuximab aerosols, protein aggregation, and the immunological and pharmacological properties of nebulized cetuximab.

\section{Aerosol characteristics}

Because precipitates were observed in the liquid phase recovered from Impinger after the generation of aerosol particles with some nebulizers, solutions were observed with an optical microscope. Whereas solutions obtained after nebulization with the AeronebPro ${ }^{\circledR}$ device remained comparable to the native medication, both the jet and the ultrasonic nebulizers resulted in the formation of insoluble particles (Figure 1). As revealed by a BCA protein assay performed on the solid fraction, the insoluble particles contained proteins (data not shown). This result indicates that immunoglobulin aggregates were formed in the liquid phase after nebulization of cetuximab with both the ultrasonic and jet devices. As shown in Table 1, the SYST'AM $^{\circledR}$ LS290 induced the formation of more and larger aggregates than the PARI $\mathrm{LC}+{ }^{\circledR}$. However, the increased temperature in the medication compartment (reaching approximately $30^{\circ} \mathrm{C}$ ) after 20 minutes of operation that was observed with the SYST' $\mathrm{AM}^{\circledR}$ LS290 was not responsible for the numerous aggregates formation since incubation of cetuximab solution during 20 minutes at $37^{\circ} \mathrm{C}$ in a water bath, did not result in the generation of insoluble particles.

To determine particle size, cetuximab aerosols were drawn through a ten-stage cascade impactor. Because insoluble aggregates were observed following resuspension of cetuximab 
from each stage in PBS in some cases, SDS $1 \%$ was added in the saline solution to dissolve the aggregates and allow the quantification of antibody on each stage. Although small differences were observed in the particle size and FPF with the three nebulizers (Table 2), all MMAD and FPF ranged from 1.6 to $2.7 \mu \mathrm{m}$ and 58 to $84 \%$ respectively, which are well suited particle sizes for pulmonary deposition within the respiratory zone (2).

To determine the biological impact of nebulizers on anticancer antibodies, we analyzed both the immunological and pharmacological properties of aerosolized-cetuximab in cell assays. In all the experiments, cetuximab was recovered as a liquid solution with Impinger following nebulization with the various devices. The effects observed with the SYST'AM ${ }^{\circledR}$ LS290generated cetuximab aerosol on cells were variable, either increased or reduced compared to the native cetuximab. This discrepancy is most likely attributed to the presence of aggregates, and thus resulted in the disqualification of the ultrasonic device for further analysis.

\section{Evaluation of aerosolized cetuximab affinity to EGFR}

Cetuximab is a chimeric antibody that binds to EGFR, a type I transmembrane receptor overexpressed in numerous human tumors including ovary or lung carcinomas (29). To determine whether nebulization modified the binding of cetuximab to EGFR, flow cytometry analysis was performed on two cell lines known to express this receptor: A549, a non small cell lung cancer line and A431, cells derived from an epidermoid carcinoma (30).

As shown in figure 2, the histogram profiles of cells are unchanged with comparable means of fluorescencewhether the cells are labeled with native or aerosolized cetuximab, indicating that nebulization with either the mesh or the jet device did not alter mAb binding to EGFR. To gain insight into the impact of nebulization on the immunological properties of cetuximab, the 
binding of cetuximab to EGFR was assessed by competition assay on A431 cells using a FITC-labeled cetuximab. Figure 3 showed that native and aerosolized cetuximab display similar means of fluorescence, with IC50 values comprised between $1.6510^{-4}$ and $1.910^{-4}$ $\mathrm{mg} / \mathrm{mL}$.

\section{Capacity of aerosolized cetuximab to interfere with EGFR transduction pathway}

In agreement with previous reports, we found that non-small cell lung cancer cell lines (A549, H460) (data not shown) displayed a limited response to cetuximab in vitro (30). Thus, the nebulization effect on the pharmacological properties of cetuximab was analyzed using the highly sensitive A431 cells.

Cetuximab binding to EGFR is expected to block ligand-receptor interaction, therefore preventing receptor phosphorylation and blocking signaling pathways $(31,32)$.

When A431 were incubated with recombinant EGF (10 ng/mL) for 10 minutes, EGFR phosphorylation was increased (data not shown). Pre-incubation of cells with native cetuximab $(50 \mu \mathrm{g} / \mathrm{mL})$ limited EGFR phosphorylation by subsequent addition of EGF (figure 4). Moreover, both AeronebPro®- PARI LC $+{ }^{\circledR}$-nebulized cetuximab led to a decrease in EGFR phosphorylation after ligand stimulation that was comparable to the native antibody.

\section{Ability of aerosolized cetuximab to inhibit tumor cell growth}

As previously shown, the stimulation of EGFR by its natural ligands enhances cell proliferation, and cell growth is potently inhibited by EGFR inhibitors such as cetuximab (32). In this study, we investigated the anti-proliferative effect of native and aerosolized cetuximab in A431 by counting cells after 48 hours treatment with the antibody. As shown in figure 5, native cetuximab induced a 45 to $50 \%$ growth inhibition in A431 cells and 
cetuximab nebulized with either AeronebPro ${ }^{\circledR}$ or PARI LC $+{ }^{\circledR}$ were similarly potent in suppressing A431 proliferation. 


\section{Discussion}

In the present study, we analyzed the feasibility of nebulizing fully-active therapeutic antibodies, a class of drugs undergoing major development in medical oncology. As a model, we chose cetuximab, an anti-EGFR chimeric IgG1 which prevents the binding of EGFR natural ligands, therefore preventing receptor activation and blocking signaling pathways leading to tumor cell growth and survival (33).

At the present time, two types of devices have been tested for macromolecule administration in the conducting airways: dry-powder inhalers that deliver solid aerosols and nebulizers resulting in the administration of drug droplets $(4,6,19-21)$. Despite the approval of drypowder inhalers for administration of locally-acting drugs in asthma and chronic obstructive pulmonary diseases, these devices have important limitations for antibody aerosolization. Anticancer antibodies, whether they are naked or conjugated (with the exception of trastuzumab (Herceptin ${ }^{\circledR}$ ) and gemtuzumab ozogamycin (Mylotarg $\left.{ }^{\circledR}\right)$ ), are generally supplied as liquids, but spray-drying of pure proteins in aqueous solutions often produces aggregates and/or loss of activity. Although the addition of disaccharides or surfactant in the medium can stabilize immunoglobulin during spray-drying, novel drug formulation must be established and evaluated (19-21, 34).

The use of nebulizers to administer anticancer antibodies is attractive since these devices offer the benefit of direct utilization of drug in solutions. However, delivery of peptides and proteins as liquid aerosols into the lungs has been largely discussed because these molecules are easily hydrolyzed within the conducting airways when they are delivered as liquid aerosols (3). Recently, a new paradigm for the pulmonary delivery of high molecular weight proteins with Fc domains emerged suggesting that it may not be the case for antibodies. Indeed, studies showed that FcRn, a transport (transcytosis) and protective pathway for 
immunoglobulins, is responsible for efficient delivery and absorption through the lungs. In addition, large proteins conjugated to the Fc domain of IgG contained in aerosol droplets have a longer half-life $(4,22,23)$. Because FcRn is expressed by epithelial cells of the upper and central airways and alveolar macrophages, this receptor might protect therapeutic mAbs administered as liquid aerosols from intracellular degradation, favor direct uptake of the drug by tumor cells derived from epithelial cells, or transport it across the lung epithelial barrier into the pulmonary bloodstream that supplies tumor cells. Although nebulizers might be a promising alternative to dry-powder inhalers for the pulmonary delivery of $\mathrm{mAb}$, the impact of nebulization on anticancer antibody activity remains to be fully explored.

The most important parameter to determine the successful delivery of inhaled drug into the lungs is the aerodynamical characteristics of the aerosol. Particles between $1-3 \mu \mathrm{m}$ are preferably deposited in the alveolar tissue, while particles greater than $6 \mu \mathrm{m}$ are generally swallowed rather than inhaled. To generate cetuximab aerosols, we tested three devices with different processes of nebulization. Particle size demonstrated that the three devices formed droplets of cetuximab with an aerodynamical diameter comprised between 1.6 to $2.7 \mu \mathrm{m}$, a range of size appropriate for efficient deposition at their site of action in central $(2-5 \mu \mathrm{m})$ and peripheral airways $(<2 \mu \mathrm{m})(2)$. However, the cetuximab droplets produced with AeronebPro ${ }^{\circledR}$ were slightly larger $(2.4-2.7 \mu \mathrm{m})$ than with the other devices. Interestingly, Bitonti and Dumont suggest that fine particle aerosols targeting proteins to the alveolar space is not crucial for efficient lung deposition and absorption of large proteins (such as erythropoietin) conjugated to the Fc domain of $\mathrm{IgG}$, because FcRn, the appropriate carrier-mediated transport system, is mainly expressed by the epithelial cells of the upper/central airways (4). Thus, the droplet size of AeronebPro ${ }^{\circledR}$-cetuximab may become a major asset to allow IgG transport/protection by FcRn. Further experiments will be required to define FcRn expression 
in lung cancer and determine the role of this $\mathrm{IgG}$ transporter on lung tumor uptake (intratumoral distribution) of therapeutic antibodies.

As observed, the jet and ultrasonic nebulizers produced numerous macroscopic aggregates of cetuximab in solution that were more abundant and larger with the latter device. This physical instability reaction is usually induced by a variety of physical factors, such as temperature, ionic strength, agitation, surface/interface adsorption, or simply time. In agreement with Steckel et al., a moderate rise in temperature (compared to other ultrasonic nebulizers) was measured in the medication compartment with SYST' AM ${ }^{\circledR}$ LS290 (35). However, it is not responsible for the aggregation formation since no insoluble particles were observed after incubation of native cetuximab in the same conditions in a water bath. Previous studies showed that recirculation of the aerosol droplets into the reservoir exerts high shear stress on the drugs, leading to protein denaturation and aggregation $(34,36)$. In contrast to the AeronebPro $^{\circledR}$, both the jet and the ultrasonic nebulizers have a recirculation system that might explain aggregate formation.

Surprisingly, the formation of aggregates in cetuximab solution following nebulization with the SYST'AM ${ }^{\circledR}$ LS290 and PARI-LC+ ${ }^{\circledR}$ did not correlate with an increase in aerosol particle size, as observed in the impaction results. These results suggest that the intramolecular interactions of hydrophobic regions of partially folded, unfolded or denatured IgGs that lead to aggregation formation is prevalent and favored in liquid phase (37). Impaction and rapid drying of droplets on the stages reduced aggregation formation in the impactor. Because the experiments were assessed at room temperature and relative humidity which does not mimic the $100 \%$ relative humidity and $37^{\circ} \mathrm{C}$ environment of airways, the results may not be predictive of the aerosol particle behavior inside the pulmonary tract. 
Insoluble aggregates are often constituted of denatured molecules and associated with no or reduced biological activity $(6,38)$. The experiments assessed on cells with the SYST' AM $^{\circledR}$ LS290-nebulized cetuximab resulted in unreliable results that were most likely associated with the variability in the amount of aggregates added to the cells. However, the slightly higher percentage of fluorescence inhibition observed in the competition assays with SYST' $^{\circledR} M^{\circledR}$ LS290-nebulized cetuximab following filtration on a $0.2 \mu \mathrm{m}$ membrane compared to the same concentration of unfiltrated antibody suggests that cetuximab-binding to EGFR might be less efficient if the antibody is aggregated (data not shown). Analysis of PARI LC $+{ }^{\circledR}$-aerosolized cetuximab binding to EGFR and anticancer activity demonstrated no significant difference compared to the native or AeronebPro ${ }^{\circledR}$-nebulized cetuximab, indicating that the antibody retained its immunological and pharmacological characteristics following nebulization with the jet device. However, our results did not rule out a potential loss of activity of the cetuximab contained in the aggregates since the biological effects observed might only be due to the soluble fraction of cetuximab in the solution.

As previously described with recombinant human proteins (i.e. erythropoietin- $\alpha$ ), protein denaturation, aggregation or micelle formation is also characterized by an altered immunogenicity, resulting in the generation of antibodies induced by the breakdown of immune tolerance existing normally to self-antigens (38). The mechanisms leading to the breakdown tolerance are not elucidated but mainly result in the production of binding antibodies that can either have no consequences for the patient or diminish the therapeutic potential of the drugs. Therefore, the use of appropriate nebulizers is of great importance with respect to anticancer antibody stability because formation of antibody aggregates may increase the drug immunogenicity. 
Although airways are an ideal route of administration for the local treatment of lung cancer, aerosol drug delivery and deposition within the lung remain challenging. In the conditions we tested, the mesh nebulizer AeronebPro ${ }^{\circledR}$ that has no recirculation system seemed to be the best device to deliver an anticancer antibody retaining immunological and pharmacological properties into the lungs, while creating droplets susceptible to deposition primarily in the upper/central conducting airways where FcRn is mainly express. Whereas our findings support the feasibility of nebulizing therapeutic antibodies, structural analysis of the molecules following nebulization would be useful to fully validate this concept. Further studies are also required to compare the antitumor activity and side effects of mAbs delivered via airways or systemic routes in animal models.

\section{Acknowledgements}

We thank Michèle De Monte for helpful suggestions in statistical analysis.

This work was supported by grants from Cancéropôle Grand Ouest, IFR135 (Institut Fédératif de Recherche), la Ligue contre le Cancer.

Agnès Maillet's fellowships were donated by SPLF (Société de Pneumologie de Langue Française) and Pneumologie Développement.

\section{References}

1- L.G. Collins, C. Haines, R. Perkel and R.E. Enck. Lung cancer : diagnosis and management. Am Fam Physician. 75:56-63 (2007)

2- G. Scheuch, M.J. Kohlhaeufl, P. Brand and R. Siekmeier. Clinical perspectives on pulmonary systemic and macromolecular delivery. Adv Drug Deliv Rev. 58:996-1008 (2006)

3- J.S. Patton and P.R. Byron. Inhaling medicines: delivering drugs to the body through the lungs. Nat Rev Drug Discov. 6:67-74 (2007) 
4- A.J. Bitonti and J.A. Dumont. Pulmonary administration of therapeutic proteins using an immunoglobulin transport pathway. Adv Drug Deliv Rev. 58:1106-1118 (2006)

5- J.S. Patton, C.S. Fishburn and J.G. Weers. The lungs as a portal of entry for systemic drug delivery. Proc Am Thorac Soc. 1:338-344 (2004)

6- R.U. Agu, M.I. Ugwoke, M. Armand, R. Kinget and N. Verbeke. The lung as a route for systemic delivery of therapeutic proteins and peptides. Respir Res. 2:198-209 (2001)

7- L. Fabbri. Pulmonary safety of inhaled insulins: a review of the current data. Curr Med Res Opin. 22 Suppl 3:21-28 (2006)

8- F. Gagnadoux, A. Le Pape, E. Lemarie, S. Lerondel, I. Valo, V. Leblond, J. Racineux and T. Urban. Aerosol delivery of chemotherapy in an orthotopic model of lung cancer. Eur Respir J. 26:657-661 (2005)

9- A.E. Hershey, I.D. Kurzman, L.J. Forrest, C.A. Bohling, M. Stonerook, M.E. Placke, A.R. Imondi and D.M. Vail. Inhalation chemotherapy for macroscopic primary or metastatic lung tumors: proof of principle using dogs with spontaneously occurring tumors as a model. Clin Cancer Res. 5:2653-2659 (1999)

10- N.V. Koshkina, J.C. Waldrep, L.E. Roberts, E. Golunski, S. Melton and V. Knight. Paclitaxel liposome aerosol treatment induces inhibition of pulmonary metastases in murine renal carcinoma model. Clin Cancer Res. 7:3258-3262 (2001)

11- N.V. Koshkina and E.S. Kleinerman. Aerosol gemcitabine inhibits the growth of primary osteosarcoma and osteosarcoma lung metastases. Int J Cancer. 116:458-463 (2005)

12- V. Knight, N.V. Koshkina, J.C. Waldrep, B.C. Giovanella and B.E. Gilbert. Anticancer effect of 9-nitrocamptothecin liposome aerosol on human cancer xenografts in nude mice. Cancer Chemother Pharmacol. 44:177-186 (1999)

13- P.M. Anderson, S.N. Markovic, J.A. Sloan, M.L. Clawson, M. Wylam, C.A. Arndt, W.A. Smithson, P. Burch, M. Gornet and E. Rahman. Aerosol granulocyte macrophage-colony stimulating factor: a low toxicity, lung-specific biological therapy in patients with lung metastases. Clin Cancer Res. 5:2316-2323 (1999)

14- C.F. Verschraegen, B.E. Gilbert, E. Loyer, A. Huaringa, G. Walsh, R.A. Newman and V. Knight. Clinical evaluation of the delivery and safety of aerosolized liposomal 9-nitro-20(s)camptothecin in patients with advanced pulmonary malignancies. Clin Cancer Res. 10:23192326 (2004)

15- G.A. Otterson, M.A. Villalona-Calero, S. Sharma, M.G. Kris, A. Imondi, M. Gerber, D.A. White, M.J. Ratain, J.H. Schiller, A. Sandler, M. Kraut, S. Mani and J.R. Murren. Phase I study of inhaled doxorubicin for patients with metastatic tumors to the lungs. Clin Cancer Res. 13:1246-1252 (2007)

16- B.P.H. Wittgen, P.W.A. Kunst, K. van der Born, A.W. van Wijk, W. Perkins, F.G. Pilkiewicz, R. Perez-Soler, S. Nicholson, G.J. Peters and P.E. Postmus. Phase I study of 
aerosolized slit cisplatin in the treatment of patients with carcinoma of the lung. Clin Cancer Res. 13:2414-2421 (2007)

17- M.Z. Lin, M.A. Teitell and G.J. Schiller. The evolution of antibodies into versatile tumortargeting agents. Clin Cancer Res. 11:129-38 (2005)

18- M.S. Nayeem and R.H. Khan. Recombinant antibodies in cancer therapy. Curr Protein Pept Sci. 7:165-170 (2006)

19- L. Dellamary, D.J. Smith, A. Bloom, S. Bot, G. Guo, H. Deshmuk, M. Costello and A. Bot. Rational design of solid aerosols for immunoglobulin delivery by modulation of aerodynamic and release characteristics. J Control Release. 95:489-500 (2004)

20- S. Schule, W. Friess, K. Bechtold-Peters and P. Garidel. Conformational analysis of protein secondary structure during spray-drying of antibody/mannitol formulations. Eur $\mathbf{J}$ Pharm Biopharm. 65:1-9 (2007)

21- M. Maury, K. Murphy, S. Kumar, A. Mauerer and G. Lee. Spray-drying of proteins: effects of sorbitol and trehalose on aggregation and FT-IR amide I spectrum of an immunoglobulin G. Eur J Pharm Biopharm. 59:251-261 (2005)

22- A.J. Bitonti, J.A. Dumont, S.C. Low, R.T. Peters, K.E. Kropp, V.J. Palombella, J.M. Stattel, Y. Lu, C.A. Tan, J.J. Song, A.M. Garcia, N.E. Simister, G.M. Spiekermann, W.I. Lencer and R.S. Blumberg. Pulmonary delivery of an erythropoietin Fc fusion protein in nonhuman primates through an immunoglobulin transport pathway. Proc Natl Acad Sci U S A. 101: 9763-9768 (2004)

23- S.C. Low, S.L. Nunes, A.J. Bitonti and J.A. Dumont. Oral and pulmonary delivery of fshFc fusion proteins via neonatal Fc receptor-mediated transcytosis. Hum Reprod. 20:1805$1813(2005)$

24- N. Hanna, R. Lilenbaum, R. Ansari, T. Lynch, R. Govindan, P.A. Janne and P. Bonomi. Phase II trial of cetuximab in patients with previously treated non-small-cell lung cancer. J Clin Oncol. 24:5253-8 (2006)

25- J.V. Heymach, M. Nilsson, G. Blumenschein, V. Papadimitrakopoulou and R. Herbst. Epidermal growth factor receptor inhibitors in development for the treatment of non-small cell lung cancer. Clin Cancer Res. 12:4441s-4445s (2006)

26- R.C. Lilenbaum. The evolving role of cetuximab in non-small cell lung cancer. Clin Cancer Res. 12: 4432s-4435s (2006)

27- D.D. Miller, M.M. Amin, L.B. Palmer, A.R. Shah and G.C. Smaldone. Aerosol delivery and modern mechanical ventilation: in vitro/in vivo evaluation. Am J Respir Crit Care Med. 168:1205-1209 (2003)

28- L. Vecellio None, D. Grimbert, M.H. Becquemin, E. Boissinot, A. Le Pape, E. Lemarie and P. Diot. Validation of laser diffraction method as a substitute for cascade impaction in the european project for a nebulizer standard. J Aerosol Med. 14:107-114 (2001) 
29- D.S. Salomon, R. Brandt, F. Ciardiello and N. Normanno. Epidermal growth factorrelated peptides and their receptors in human malignancies. Crit Rev Oncol Hematol. 19:183$232(1995)$

30- M.L. Janmaat, F.A.E. Kruyt, J.A. Rodriguez and G. Giaccone. Response to epidermal growth factor receptor inhibitors in non-small cell lung cancer cells: limited antiproliferative effects and absence of apoptosis associated with persistent activity of extracellular signalregulated kinase or akt kinase pathways. Clin Cancer Res. 9:2316-2326 (2003)

31- G.N. Gill, T. Kawamoto, C. Cochet, A. Le, J.D. Sato, H. Masui, C. McLeod and J. Mendelsohn. Monoclonal anti-epidermal growth factor receptor antibodies which are inhibitors of epidermal growth factor binding and antagonists of epidermal growth factor binding and antagonists of epidermal growth factor-stimulated tyrosine protein kinase activity. J Biol Chem. 259:7755-7760 (1984)

32- W.K. Bleeker, J.J. Lammerts van Bueren, H.H. van Ojik, A.F. Gerritsen, M. Pluyter, M. Houtkamp, E. Halk, J. Goldstein, J. Schuurman, M.A. van Dijk, J.G.J. van de Winkel and P.W.H.I. Parren. Dual mode of action of a human anti-epidermal growth factor receptor monoclonal antibody for cancer therapy. J Immunol. 173:4699-4707 (2004)

33- J. Baselga. The EGFR as a target for anticancer therapy-focus on cetuximab. Eur $\mathbf{J}$ Cancer. 37 Suppl 4:16-22 (2001)

34- R.U. Agu, S. Valiveti, K.S. Paudel, M. Klausner, P.J. Hayden and A.L. Stinchcomb. Permeation of win 55,212-2, a potent cannabinoid receptor agonist, across human tracheobronchial tissue in vitro and rat nasal epithelium vivo. J Pharm Pharmacol. 58:1459-1465 (2006)

35- H. Steckel and F. Eskandar. Factors affecting aerosol performance during nebulization with jet and ultrasonic nebulizers. Eur J Pharm Sci. 19: 443-455 (2003)

36- I. Fangmark and J. C. Carpin. Protein nebulization. J. Aerosol Sci. 27:231-232 (1996)

37- H.C. Mahler, R. Müller, W. Frie $\beta$, A. Delille and S. Matheus. Induction and analysis of aggregates in aliquid IgG1-antibody formulation. Eur J Pharm Biopharm. 59(3):407-17 (2005).

38- H. Schellekens. Factors influencing the immunogenicity of therapeutic proteins. Nephrol Dial Transplant. 6:3-9 (2005) 


\section{Figures caption}

Figure 1: Aggregates in cetuximab solution after nebulization.

Aggregates were observed under an optical microscope (on the left cetuximab aerosolized with the PARI LC+ ${ }^{\circledR}$ and with the SYST'AM ${ }^{\circledR}$ LS290 on the right).

\section{Figure 2: Binding of cetuximab to EGFR following nebulization.}

A431 (A) or A549 (B) were respectively incubated with $10 \mu \mathrm{g} / \mathrm{mL}$ or $2 \mu \mathrm{g} / \mathrm{mL}$ cetuximab or matched control isotype. Subsequently, followed by incubation with FITC-F(ab')2 antihuman IgG and then analyzed by flow cytometry. Isotype control antibody histograms are indicated as gray line and cetuximab treated samples as black line. Mean fluorescence is indicated in the upper corner of the histograms.

\section{Figure 3: Evaluation of aerosolized cetuximab affinity to EGFR.}

A431 cells were incubated with FITC-cetuximab $(5 \mu \mathrm{g} / \mathrm{mL})$ or with matched control FITCrituximab and then, with unlabeled cetuximab $\left(5 \cdot 10^{-6}\right.$ to $\left.5 \cdot 10^{-2} \mathrm{mg} / \mathrm{mL}\right)$. Cells were analyzed by flow cytometry. Results of cells treated with cetuximab are indicated as dashed line, with cetuximab nebulized by AeronebPro and PARI LC+ as solid and dotted line respectively.

\section{Figure 4: Aerosolized cetuximab inhibits EGFR phosphorylation.}

$4.10^{5}$ A431 were seeded on a 6-well plate and treated with cetuximab $(50 \mu \mathrm{g} / \mathrm{mL})$ for $24 \mathrm{~h}$. Cells were then incubated with $10 \mathrm{ng} / \mathrm{mL}$ recombinant EGF for 10 minutes and lysed. Immunoblots of protein lysates were analyzed for phosphorylated and total EGFR. Results are representative of one experiment out of at least three independent experiments showing similar profile. 


\section{Figure 5: Effect of cetuximab on A431 cells proliferation.}

Cells (5.000 cells per well in a 96 -well plate) were treated for $48 \mathrm{~h}$ with cetuximab $(50 \mu \mathrm{g} / \mathrm{mL})$ and then counted using a Malassez cell. Results are expressed as median of the percents of relative growth and are representative of six independent experiments. $\bullet p<0.025$ vs. control 
Click here to download Figure: Figure 1.ppt
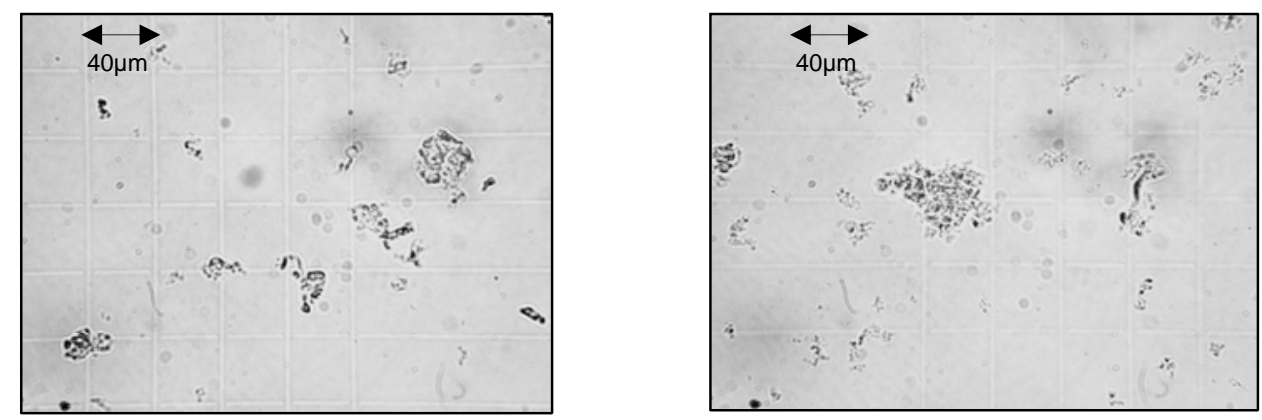

Figure 1 : Aggregates in cetuximab solution after nebulization. 
Table 1: Q uantity of cetuximab aggregates in solution after nebulization.

\begin{tabular}{|c|c|c|c|}
\hline \multirow[t]{2}{*}{ Experiment } & 1 & 2 & 3 \\
\hline & \multicolumn{3}{|c|}{ Aggregates per mL } \\
\hline Native cetuximab & 0 & 0 & 0 \\
\hline Cetuximab AeronebPro & 0 & -1000 & -2000 \\
\hline Cetuximab PARI LC+ & \multicolumn{3}{|c|}{$380000-490000-610000$} \\
\hline Cetuximab SYST'AM & \multicolumn{3}{|c|}{$840000-990000-1510000$} \\
\hline
\end{tabular}

Nebulizations were performed as described in Material and Methods. Aggregates were counted under an optical microscope using a Malassez cell. The results are expressed as number of aggregates per $\mathrm{mL}$, counted in at least three independent experiments. 
Click here to download Table: Table 2.doc

Table 2: Aerodynamical characteristics of cetuximab aerosols.

\begin{tabular}{lcc}
\hline & MMAD $(\mu \mathrm{m})$ & Fine Particule Fraction $(\%)$ \\
\hline AeronebPro & 2.4 & 74 \\
& 2.7 & 58 \\
& 2.6 & 58 \\
PARI LC+ & 2.3 & 77 \\
& 1.7 & 82 \\
& 1.7 & 82 \\
SYST'AM & 2 & 74 \\
& 1.6 & 84 \\
& 1.7 & 80 \\
\hline
\end{tabular}


A. A431
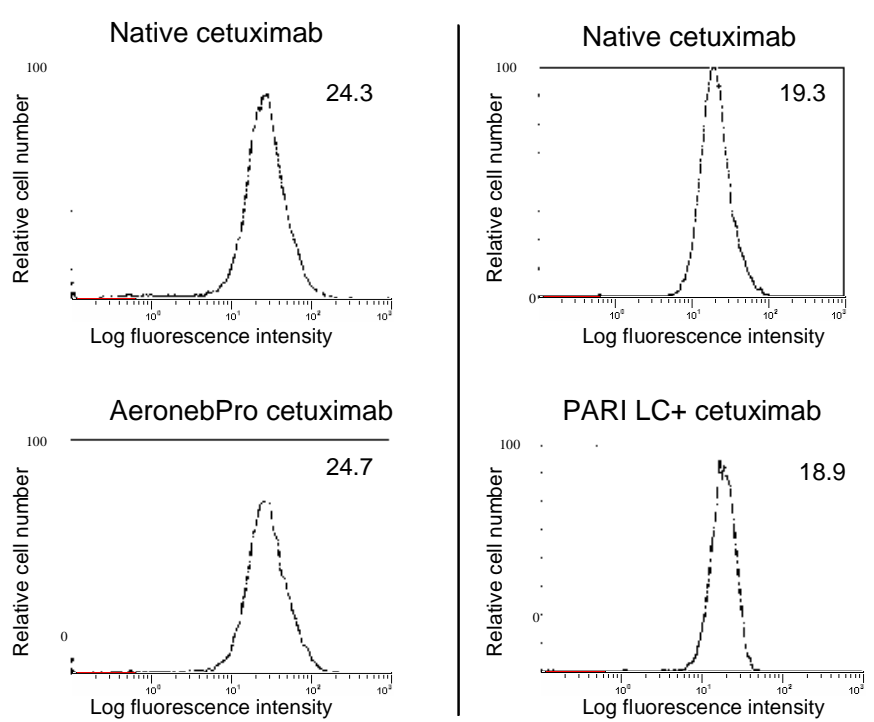

B. A549

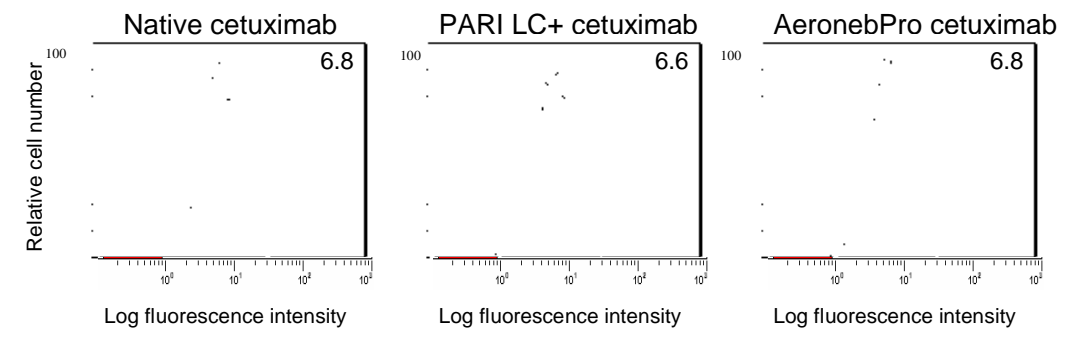

Figure $2 Q$ Binding of cetuximab to EGFR following nebulization. 


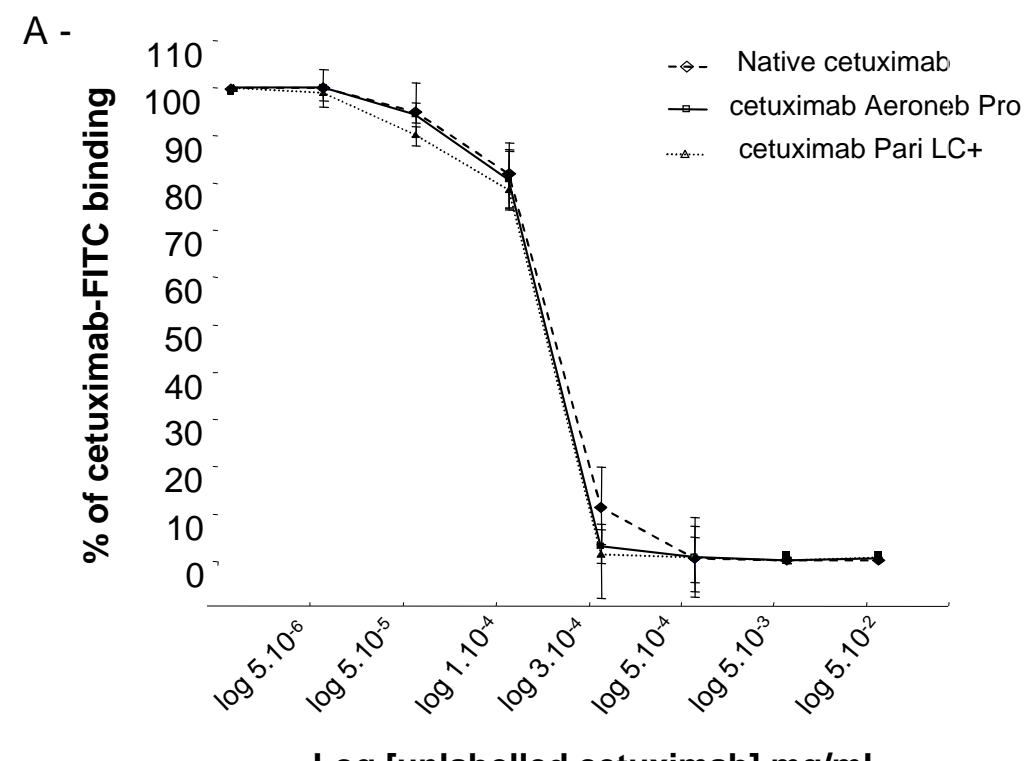

\begin{tabular}{|c|c|}
\hline & IC50 $(\mathrm{mg} / \mathrm{mL})$ \\
\hline Native cetuximab & $1.910^{-4}$ \\
\hline $\begin{array}{c}\text { Cetuximab } \\
\text { AeronebPro }\end{array}$ & $1.710^{-4}$ \\
\hline Cetuximab PARI LC+ & $1.6510^{-4}$ \\
\hline
\end{tabular}

Log [unlabelled cetuximab] $\mathrm{mg} / \mathrm{mL}$

Figure 3 : Evaluation of cetuximab affinity following nebulization. 
Figure 4

Click here to download Figure: Figure 4.ppt

A431

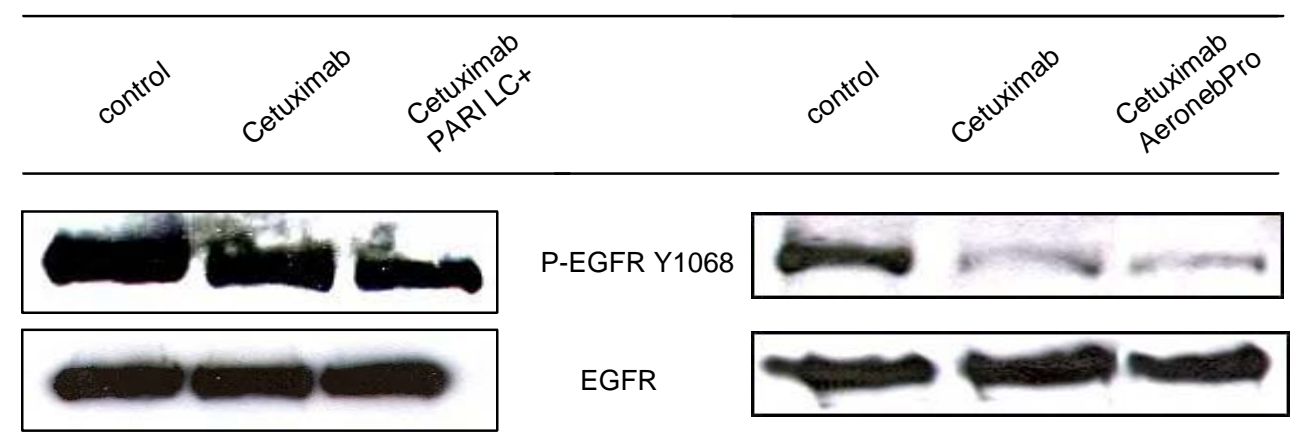

Figure 4 : Aerosolized cetuximab inhibits EGFR phosphorylation.
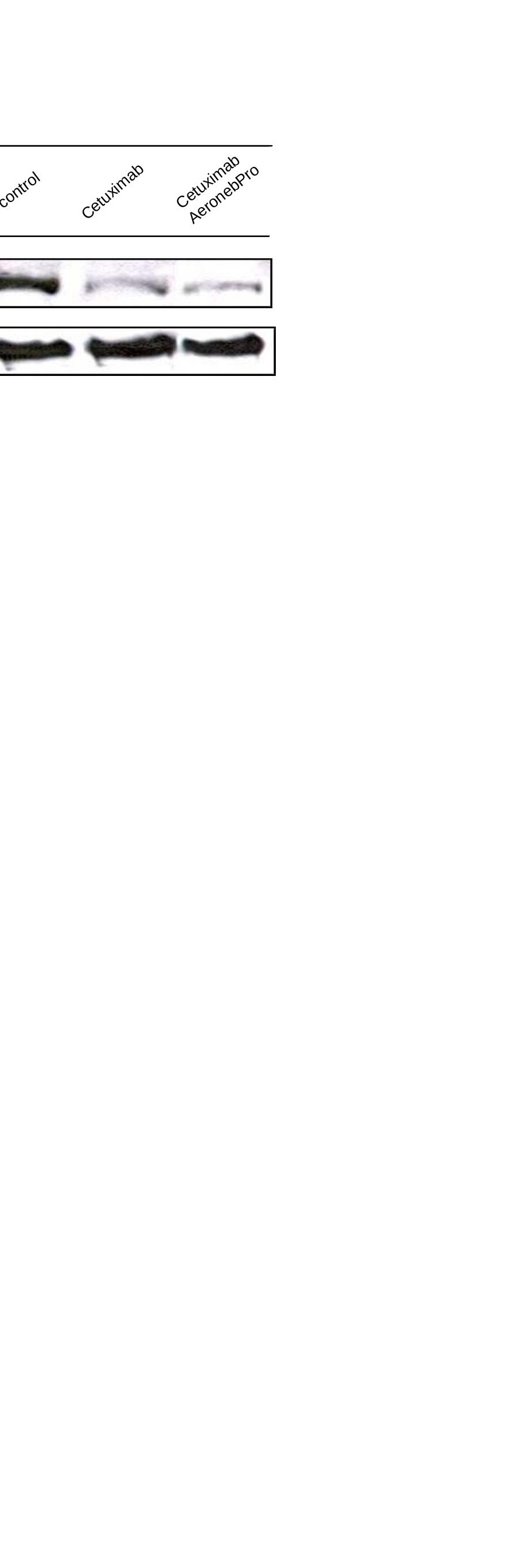


\section{Figure 5}

Click here to download Figure: Figure 5.ppt

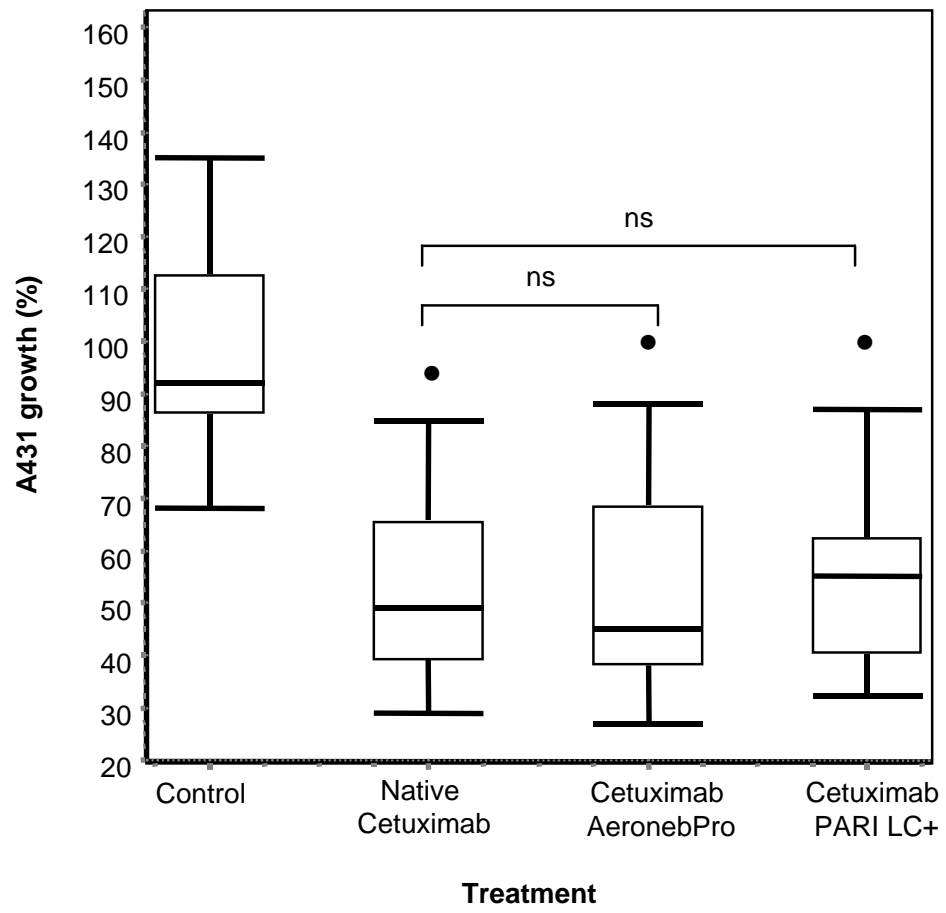

Figure 5 : Effect of cetuximab on A431 cell proliferation. 